\title{
Exploration on Informatization Mode of Teaching Skill Training in Normal Universities Based on Information Technology
}

\author{
Hongyun Chen ${ }^{1 *}$, Junling Huang ${ }^{1}$, Yuping Yang ${ }^{1}$, Feng Zhao ${ }^{1}$ \\ ${ }^{I}$ School of Chemistry and Chemical Engineering, Jiangxi Science and Technology Normal University, Nanchang, \\ China \\ "Corresponding author. Email: chenhongyun92@126.com
}

\begin{abstract}
As pre service teachers, the improvement of normal students' information-based teaching ability and the extension of practical application ability play a strong role in promoting the construction of educational informatization in China. Therefore, normal universities need to integrate information technology into the teaching skills training course to Cultivate Normal Students' teaching ability. In view of the problems existing in the current practical training of teaching skills, five practical training platforms, namely "information release and management platform", "micro teaching platform", "education internship platform", "task driven and cooperative learning platform" and "practical training process evaluation system platform", have been established by using information technology means, and an information-based training mode for practical training of teaching skills in normal universities has been constructed. It solves the practical teaching problems and effectively promotes the development of normal students' information-based teaching ability facing the core literacy.
\end{abstract}

Keywords: Normal university teaching, Skill training, Information model

\section{INTRODUCTION}

With the advent of the intelligent age, educational informatization in China has also embarked on a new journey in the intelligent age. In April 2018, the Ministry of Education issued the action plan for educational informatization 2.0, which clearly emphasized the need to strengthen the cultivation of information literacy and information-based teaching ability of normal students. In the key points of work in 2019, the Ministry of education will "promote the integration of information technology and education and teaching, promote the transformation and upgrading of educational informatization, and start the project for improving the application ability of information technology of primary and secondary school teachers 2.0" As one of the foundations for consolidating educational development[1].

Teaching skills are the most basic quality for normal students to go to teaching posts. In the context of the new curriculum, the cultivation of normal students' basic teaching skills needs to be based on teaching practice, organically combine information technology, information resources, microteaching, educational internship and curriculum in the process of teaching skills training, and construct effective teaching methods and evaluation methods, including teaching preparation, classroom teaching process and teaching evaluation, which can finally promote students' effective learning[2]. The use of information technology can effectively support teaching. Modular teaching is conducive to the real implementation of teaching skills training and improve the quality of practical teaching[3].

In view of the four prominent problems existing in the current teaching skills training of normal college students, such as "too little time for teaching skills training, single training form and teaching method, single evaluation, and poor adaptability of normal college students in the real classroom", this achievement explores an effective training mode to solve practical teaching problems; Improve the teaching methods and means of practical training of teaching skills; change the evaluation method of practical training of chemistry teaching skills; better combine the dominant position of students with the dominant position of teachers to 
improve the comprehensive professional ability of normal students and adapt to the reform of basic education.

\section{INFORMATIZATION MODEL OF TEACHING SKILLS TRAINING IN NORMAL UNIVERSITIES}

The informatization model of teaching skill training is a new model of teaching skill training based on how to cultivate high-quality and strong skill normal students[4]. Practical training mode solves practical teaching problems: improving teaching skills, practical teaching methods and means; change the evaluation method of practical training of chemistry teaching skills; better combine the dominant position of students with the dominant position of teachers to improve the comprehensive professional ability of normal students and adapt to the reform of basic education. The training mode creates a learning community and five training platforms, including "information release and management platform", "micro teaching platform", "education internship platform", "task driven and cooperative learning platform" and "training process evaluation system platform".

\subsection{Training Concept of "One Fundamental and Three Skills"}

Taking "one fundamental: student-oriented, three skills: teaching skills, post acquisition skills and design analysis skills" as the practical training concept of teaching skills in normal universities, teaching skills training is carried out around student-oriented, learning based teaching and training based on needs. Focusing on the cultivation of information-based teaching ability, taking the two aspects of design and analysis skills and teaching post acquisition skills as the teaching skills training objectives, the training contents of three stages are determined according to the teaching objectives. The teaching content of each stage is divided into three modules to increase the training of new teaching skills to adapt to the new curriculum of basic education.

\section{2. "One Learning Community" "Task Driven and Cooperative Learning Mode Platform"}

Learning community is an organization in which normal students and instructors learn together because of their common mission and common desire. Teachers and students in the community share their interest in learning, jointly look for the journey to knowledge and participate together. Learning community is the realization condition of training mode, which mainly includes the following two levels. Knowledge community: teachers and students create knowledge, share knowledge, promote understanding and improve together; Learner community refers to a social and cultural atmosphere formed by the interaction between students and teachers, students and students. It is an indispensable psychological factor in the process of training and the embodiment of the relationship between teacher-student training and student-student training.

The cultivation of information-based teaching ability is an ecological community from mastering information-based knowledge to experiential learning, self-evaluation and reflection in the process of teaching practice, and gradually forms multi-party cooperation and communication. It has the characteristics of integrity, linkage and dynamics. Strengthen the communication between teachers and students. In the teaching skills training courses of normal students, adopt the dual tutorial system, and combine the college instructors with the middle school instructors. The theoretical problems can be solved by consulting the professional teachers of the college, and the problems found in the process of practice can be consulted and discussed by the internship instructor. Giving full play to the guiding role of double tutors is related to the effectiveness of normal students' teaching ability and the improvement of normal students' educational technology ability.

In the process of practical training, the learning community constructs the way of students' independent exploration and cooperative learning through task driven and cooperative learning: creating training situations clarifying learning tasks - using learning resources to study - group cooperation and communication observing expert teaching cases - teaching practice Evaluation and re practice. Cultivate normal students' information literacy and comprehensive teaching quality, and promote the formation of skills.

\subsection{Practical teaching methods: three implementation platforms}

The training teaching method is realized through three implementation platforms, including training information release and management platform, microteaching platform and education internship platform.

\subsubsection{Training information release and management platform}

Relying on the school's network teaching platform and learning wechat group, build the teaching skills training network course, create the training blog and display the members' teaching achievements. On this platform, taking the individual students as the unit, we grasp the degree of teaching skills that normal students have mastered, and realize the practical training release and management informatization of teaching skills[5]. In order to make the teaching skills training website and wechat management platform play their due role in information construction, we also need to strengthen the 
website management to ensure its safe and effective operation.

\subsubsection{Microteaching platform}

Microteaching is a systematic method to train normal students' teaching skills by using modern teaching technology. Microteaching is a reduced and controllable teaching environment. Microteaching actually provides an exercise environment to simplify daily complex classroom teaching and enable practitioners to get a lot of feedback.

Using the micro-classroom of the school, a group of 10 people will train the teaching skills in the first and second stages of the teaching skills training course. The situation of the trial speaker is recorded by the video recorder, watched by teachers and students, analyzed the advantages and disadvantages together, and then trained until they master the correct teaching skills. The Microteaching platform plays a significant role in the training of students' teaching behavior.

\subsubsection{Education internship platform}

Educational probation is the observation and analysis of normal students' work in all aspects of middle school teaching and school life under the guidance of teachers. The purpose is to enrich students' perceptual knowledge, deepen students' understanding of theory, inspire students' thoughts and feelings of loving educational work, and cultivate students' observation and analysis ability.

Use educational probation to observe the teaching of middle school teachers and conduct classroom evaluation. Combine microteaching with educational probation for practical training, and carry out the second and third stage of the training course[6]. It overcomes the current situation that the practical training of chemistry teaching skills is lack of real classroom practical training.

On the basis of study and observation, individual teaching skills training is carried out to transform theory into practice. The micro classroom is composed of teachers, students and teaching evaluators to truly experience teaching. Finally, it comments on the teaching skills of normal students according to the practice, so that the trainees can get feedback information in time and accurately. According to the problems found in self-analysis, discussion and evaluation, the trainees modify the teaching plan and prepare for the recycling and re practice of Microteaching.

When the individual teaching skills are skilled, prepare for class speaking training. Give two complete classes according to the teaching ideas. After the trial lecture, go to the middle school for observation, and compare and reflect on your lessons with those of middle school expert teachers.

\subsection{Quantitative and qualitative informatization training evaluation system platform}

According to the different nature of training evaluation methods, it is divided into quantitative evaluation and qualitative evaluation. The value orientation of quantitative evaluation is "instrumental rationality", and the value orientation of qualitative evaluation is "practical rationality". The function of training quantitative evaluation is mainly to distinguish, distinguish and identify. The main function of training qualitative evaluation is communication, reflection and improvement.

The evaluation methods of training mode are qualitative evaluation based on electronic archives and quantitative evaluation based on Electronic Gauges. Use the network teaching platform to create training blogs and training electronic files. Establish an electronic folder evaluation space for each collaborative group to evaluate and reflect on the whole learning process.

\section{APPLICATION EFFECT OF INFORMATIZATION TRAINING MODE}

Through the systematic learning and skill training of this course, normal students' ability to use knowledge and competitive level have been greatly improved. In the past two years, our undergraduates have won awards in a series of discipline knowledge and skill competitions, showing strong discipline knowledge application ability and high academic competition level. The students performed well in the educational practice, and the tutors of the internship school rated the students internship results as more than 93 points per capita.

Through the joint training of colleges and middle schools, students have widely obtained the latest research information on the reform and development of middle school chemistry teaching, shortened the cognitive distance, improved the teaching quality of subject teaching theory and the comprehensive ability and professional quality of normal students. The survey shows that the employment rate of normal graduates of our college has remained stable at more than $92 \%$ in recent years. Most students have passed the national recruitment to middle school teaching posts. Normal students of chemistry college are generally welcomed by employers.

\section{CONCLUSION}

The information-based teaching mode of teaching skills training based on information technology has achieved good results[7]. The use of information technology to improve teaching and learning methods, provide students with more opportunities for hands-on 
practice, and make up for some deficiencies in the training courses. In the three links before class, in class and after class, the information technology is applied to the practical teaching of teaching skills, which exercises students' self-study and practical ability, and effectively improves the quality of practical teaching of teaching skills.

This achievement has been explored and practiced for 4 years. In order to improve the teaching skills of normal college students and adapt to the comprehensive professional ability of the new curriculum of basic education, change the current situation of too little teaching skills training time and single evaluation, and enhance the adaptability of normal college students in the real classroom. It is proposed to organically combine information technology, information resources, microteaching, educational internship and curriculum in the process of teaching skills training, construct an effective chemical teaching skills training mode platform, improve the classroom teaching process and teaching evaluation, and finally promote students' effective learning. After three years of teaching practice, it has achieved remarkable results, recognized by students, peers and experts, and has been popularized and applied.

However, the cultivation of information-based teaching ability should not only be in the classroom, but also expand to the broad stage of educational practice. The complex and changeable practice situation is the experience field of wisdom generation, and the accumulation and precipitation of time is the necessary process of wisdom sublimation. Therefore, in the future, we still need to continue to track and practice, and constantly optimize the generation strategy, so as to provide reference for the reform of normal students' education.

\section{ACKNOWLEDGMENTS}

2020 Jiangxi Province degree and postgraduate education and teaching reform research project "OBE oriented master of education mixed chemistry education curriculum group construction and teaching reform research" ( JXYJG-2020-155 ) ; 2020 Jiangxi basic education research project "research and practice of part-time master of chemistry education based on OBE orientation" (SZUJKHX2020-974); 2020 Jiangxi basic education research project "Research on curriculum construction and teaching practice of hybrid chemistry teacher education based on gold curriculum standard"

(SZUJKHX2020-943).

\section{REFERENCES}

[1] Ministry of education. Key points of the Ministry of education in 2019, [ EB/OL. (2019-02-22) [2019-02-26]. http: / /www. moe. gov. cn /jyb_xwfb /gzdt_gzdt/ s5987 /201902 /t20190222_370722. html).

[2] Zhong Z. X. (2006) Informational teaching mode. Beijing Normal University Press, Beijing.

[3] Liu Z. X. (2018) Chemistry teaching theory. Higher Education Press, Beijing.

[4] Wang L. (2009) Research on chemistry experiment and teaching in middle school. Beijing Normal University Press, Beijing.

[5] Zhang w. H. et al. (2011), Research on Curriculum Integration of Information Technology and Teaching Skills of Chemistry and its Practice. Journal of Higher Education of Sciences, Vol. 06:130-134.

[6] Li Guo.\& Xu X. D. (2003) Design of E-Portfolio learning evaluation based on inter-school cooperation of web. Journal of China Educational Technology, Vol. 12: 72-75.

[7] Jiubiao Cheng. The Improved Microteaching Pattern of Getting Used to the Training of the Tryout Teaching and Classroom Teaching Skills. Journal of Modern Educational Technology, Vol.8 (2009), p. 112-115. 